\title{
Diepoxyactinorhodin: a new pyranonaphthoquinone dimer from Streptomyces sp.
}

\author{
Kazuya Nakagawa ${ }^{1}$, Yoshiaki Hiraoka ${ }^{1}$ and Nobutaka Imamura ${ }^{2}$ \\ The Journal of Antibiotics (2013) 66, 295-297; doi:10.1038/ja.2013.12; published online 27 March 2013
}

Keywords: actinorhodin; antibiotics; Streptomyces

During the course of screening for new antibiotics against grampositive bacteria such as methicillin-resistant Staphylococcus aureus, a new actinorhodin analog, diepoxyactinorhodin (compound 1) was discovered. Herein we describe the isolation, structure elucidation and biological activities of compound $\mathbf{1}$.

The strain (MC11141) used for production was isolated from a soil sample collected in Kobe City, Japan and maintained in a starch casein agar slant (1.0\% starch, $0.03 \%$ casein, $0.2 \% \mathrm{NaCl}, 0.2 \%$ $\mathrm{K}_{2} \mathrm{HPO}_{4}, 0.005 \% \mathrm{MgSO}_{4}, 0.002 \% \mathrm{CaCO}_{3}, 0.001 \% \mathrm{FeSO}_{4}, \mathrm{pH} 7.2$ ) containing $1.5 \%$ of agar. Classification of the strain was performed using $16 \mathrm{~S}$ ribosomal DNA sequence analysis with primer 10F (5'-GTT TGATCCTGGCTCA-3'), 686F (5'-TAGCGGTGAAATGCGTAGA- $\left.3^{\prime}\right)$, 800R ( $5^{\prime}$-TACCAGGGTATCTAATCC- $\left.3^{\prime}\right)$ and 1541R (5'-AAGGAGGT GATCCAGCC- $\left.3^{\prime}\right)$, which amplified the nearly complete $16 \mathrm{~S}$ ribosomal DNA gene (1218bp; gene accession no. AB751253). Comparison of the sequence from MC11141 with known sequences in the GeneBank database was carried out through a BLAST alignment search, resulting in $99.50 \% 16 \mathrm{~S}$ ribosomal DNA sequence similarities to Streptomyces prunicolor. Thus, strain MC11141 was classified as a Streptomyces species.

Starch casein medium $(200 \mathrm{ml})$ in $500-\mathrm{ml}$ Sakaguchi flasks was inoculated with pre-cultured strains $(10 \mathrm{ml}$ in starch casein medium) and incubated for 7 days at $30^{\circ} \mathrm{C}$ on a reciprocal shaker (120 r.p.m.). The filtrate of the cultured media (five flasks, 1-liter total volume) was extracted with ethyl acetate, and the organic layer was evaporated to dryness $(50.2 \mathrm{mg})$. The crude material was dissolved in $\mathrm{MeOH}$ and the solution was applied to an octadesylsilane column (Wakogel $50 \mathrm{C}_{18}$, i.d. $2 \times 15 \mathrm{~cm}$ ) and eluted with a stepwise gradient of $\mathrm{CH}_{3} \mathrm{CN}$ in $\mathrm{H}_{2} \mathrm{O}(25,50,75$ and 100\%). The eluted fractions containing 50 $75 \% \mathrm{CH}_{3} \mathrm{CN}$ were combined and evaporated in vacuo to yield a crude material $(25.6 \mathrm{mg})$. Further purification was carried out with an ODS column (Cosmosil 5C 18 -AR-II, $10 \times 250 \mathrm{~mm}$ ) on an isocratic HPLC system (GL-7410 pump with GL-7452 PDA detector, GL Science, Tokyo, Japan) using $40 \% \mathrm{CH}_{3} \mathrm{CN}$ containing $0.05 \%$ trifluoroacetic acid, which yielded an active, yellowish brown powder (compound 1,
$10.6 \mathrm{mg}$ ). Ferric chloride reactivity and a bromocresol green test on TLC indicated the presence of both a phenolic hydroxyl and carboxylic acid group, respectively.

The optical rotation and m.p. of compound 1 were as follows; $[\alpha]_{\mathrm{D}}^{25}-161$ ( $c$ 0.2 , dimethylsulphoxide) and m.p. $269-273^{\circ} \mathrm{C}$ (deg). The UV-vis spectrum of compound 1 (V-630 spectrophotometer, Jasco, Tokyo, Japan) showed maximum absorptions at $218(\log \varepsilon$; 3.96), 245 (4.10) and 433 (4.00) $\mathrm{nm}$ in $\mathrm{MeOH}$, suggesting compound $\mathbf{1}$ is a naphthoquinone-type compound, according to a search of the Dictionary of Natural Products Database. The IR spectrum of compound 1 (FT/IR-8600 spectrometer, Shimadzu, Kyoto, Japan) indicated the absorption corresponding to carboxylic acid and quinone carbonyl group ( $v_{\max }$ film; 3200 (br), 1724 (CO), 1645 (quinone) $\mathrm{cm}^{-1}$ ), supporting the presence of a carboxylic acid group and a naphthoquinone moiety. A MW of 666 (LC-ESI-MS; $\mathrm{m} / \mathrm{z} 665$ $[\mathrm{M}-\mathrm{H}]^{-}$) was determined for compound 1, whereas the molecular formula was established to be $\mathrm{C}_{32} \mathrm{H}_{26} \mathrm{O}_{16}$ based on HR- FAB -MS spectral data (found: $\mathrm{m} / z$ 665.1129 $[\mathrm{M}-\mathrm{H}]^{-}$, calc: $\mathrm{m} / \mathrm{z} 665.1143$ $[\mathrm{M}-\mathrm{H}]^{-}$) using a JMS-700T tandem mass spectrometer (JEOL, Tokyo, Japan).

The molecular formula of compound 1 predicts the presence of 32 carbon signals in a ${ }^{13} \mathrm{C}$ NMR spectrum. However, only 16 carbon signals were observed, which indicates compound 1 was likely a symmetric dimer. The ${ }^{13} \mathrm{C}$ NMR spectrum showed signals of two quinone carbonyl $\left(\delta_{\mathrm{C}} 194.4, \mathrm{C}-5\right.$ and $\left.\delta_{\mathrm{C}} 195.8, \mathrm{C}-10\right)$, one protonated aromatic carbon $\left(\delta_{\mathrm{C}} 135.4, \mathrm{C}-7\right)$ and five non-protonated aromatic carbons $\left(\delta_{\mathrm{C}} 112.1, \mathrm{C}-5 \mathrm{a}, \delta_{\mathrm{C}} 154.6, \mathrm{C}-6, \delta_{\mathrm{C}} 130.2, \mathrm{C}-8, \delta_{\mathrm{C}} 153.8, \mathrm{C}-9\right.$, and $\left.\delta_{\mathrm{C}} 112.2, \mathrm{C}-9 \mathrm{a}\right)$, implying the presence of a naphthoquinone moiety. The following signals were also observed: one carboxyl carbon $\left(\delta_{\mathrm{C}} 172.5, \mathrm{C}-13\right)$, two oxygenated-quaternary carbons $\left(\delta_{\mathrm{C}} 63.5, \mathrm{C}-4 \mathrm{a}\right.$ and $\left.\delta_{\mathrm{C}} 63.4, \mathrm{C}-10 \mathrm{a}\right)$, two oxygenated-methine carbon $\left(\delta_{\mathrm{C}} 65.0, \mathrm{C}-1\right.$ and $\left.\delta_{\mathrm{C}} 61.8, \mathrm{C}-3\right)$, two methylene $\left(\delta_{\mathrm{C}} 25.1, \mathrm{C}-4\right.$ and $\left.\delta_{\mathrm{C}} 40.8, \mathrm{C}-12\right)$ and one methyl carbon $\left(\delta_{\mathrm{C}} 15.8, \mathrm{C}-11\right)$.

The ${ }^{1} \mathrm{H}$ NMR spectrum of compound 1 was recorded on a JNMECA-600 NMR spectrometer (JEOL) and displayed signals of two

${ }^{1}$ Graduate School of Science and Engineering, Ritsumeikan University, Kusatsu, Shiga, Japan and ${ }^{2}$ Department of Pharmaceutical Sciences, Ritsumeikan University, Kusatsu, Shiga, Japan

Correspondence: Professor N Imamura, Department of Pharmaceutical Sciences, Ritsumeikan University, 1-1-1 Noji-higashi, Kusatsu, Shiga 525-8577, Japan.

E-mail: imamura@ph.ritsumei.ac.jp

Received 1 October 2012; revised 14 December 2012; accepted 11 January 2013; published online 27 March 2013 


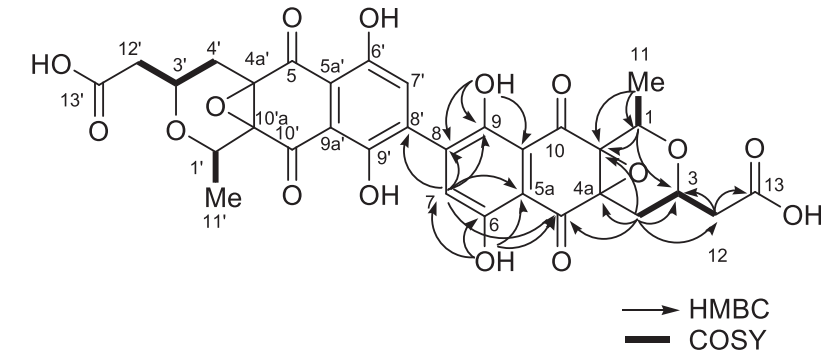

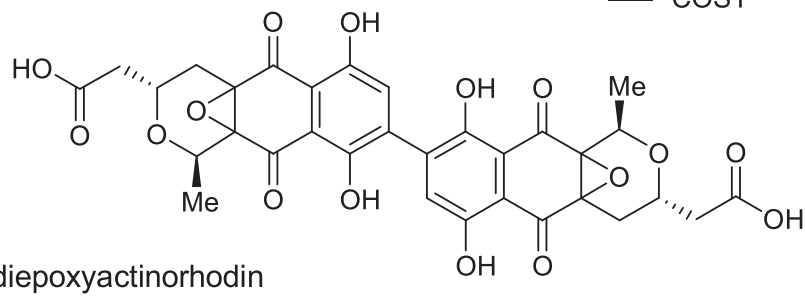

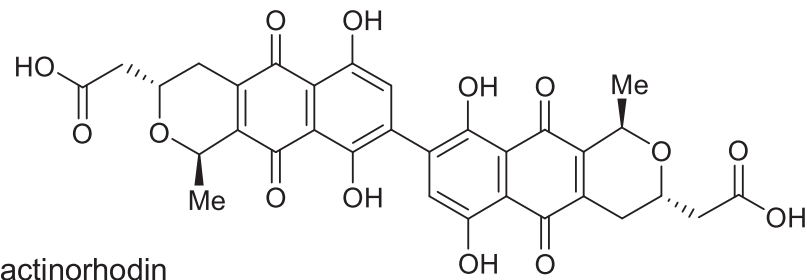

Figure 1 Summarized results of COSY and HMBC spectra of compound 1 and structures of compound 1 and actinorhodin. Correlations in COSY and HMBC spectra were demonstrated by bold lines and lines with arrowhead, respectively. hydrogen-bonded phenolic hydroxyl protons $\left(\delta_{\mathrm{H}} 11.39,9-\mathrm{OH}\right.$ and $\left.\delta_{\mathrm{H}} 11.73,6-\mathrm{OH}\right)$, a rapidly exchangeable carboxyl proton $\left(\delta_{\mathrm{H}} 12.21\right.$, $13-\mathrm{OH})$, and an aromatic proton $\left(\delta_{\mathrm{H}} 7.40, \mathrm{H}-7\right)$. Furthermore, protons from one methyl $\left(\delta_{\mathrm{H}} 1.50, \mathrm{H}-11\right)$, two methylene $\left(\delta_{\mathrm{H}} 2.65\right.$ and $1.75, \mathrm{H}-4 \alpha, \beta$ and $\delta_{\mathrm{H}} 2.25$ and $\left.2.49, \mathrm{H}-12 \alpha, \beta\right)$, and two methine $\left(\delta_{\mathrm{H}} 4.59, \mathrm{H}-1\right.$ and $\left.\delta_{\mathrm{H}} 4.04, \mathrm{H}-3\right)$ were observed. Figure 1 shows two sequences from these methylene and methyl protons (bolded lines) were indicated by following ${ }^{1} \mathrm{H}-{ }^{1} \mathrm{H}$ COSY data (H-1 to $\mathrm{H}-11 ; \mathrm{H}-4 \alpha$ to $\mathrm{H}-3$ and $\mathrm{H}-3$ to H-12 $\alpha$ ). The HMBC correlations (arrows) from these proton signals are also observed in Figure $1(\mathrm{H}-11$ to $\mathrm{C}-1$ and $\mathrm{C}-10 \mathrm{a}$; $\mathrm{H}-1$ to $\mathrm{C}-10 \mathrm{a}$ and $\mathrm{C}-3 ; \mathrm{H}-4 \alpha$ to $\mathrm{C}-3, \mathrm{C}-4 \mathrm{a}$ and $\mathrm{C}-12 ; \mathrm{H}-4 \beta$ to $\mathrm{C}-5$, $\mathrm{C}-4 \mathrm{a}$ and $\mathrm{C}-10 \mathrm{a} ; \mathrm{H}-12 \alpha$ to $\mathrm{C}-3, \mathrm{C}-4$ and $\mathrm{C}-13)$. The HMBC data indicate the presence of a carboxymethyl-methylpyran ring fused to a naphthoquinone backbone. Two oxygenated quaternary carbons (C-

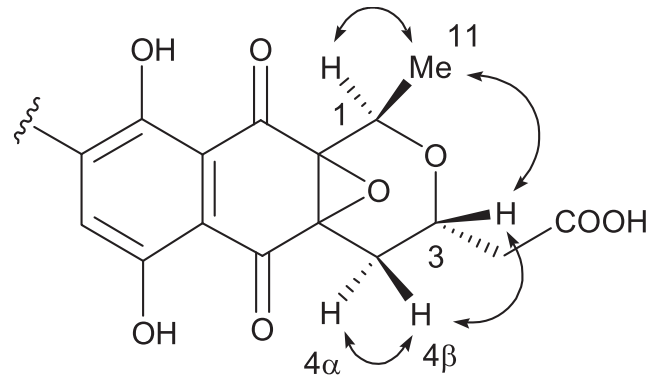

Figure 2 Summarized results of ROESY spectrum and relative configuration of compound 1 . Correlations in ROESY spectrum of compound 1 were demonstrated by lines with two arrowhead.

Table 1 NMR spectroscopic data of compound $1^{\text {a }}$

\begin{tabular}{|c|c|c|c|c|c|}
\hline Position & $\delta_{C}$ & $\delta_{H}$ & $\cos Y$ & $H M B C$ & ROESY \\
\hline 1 & 65.0 & $4.59(1 \mathrm{H}, \mathrm{q}, J=6.2 \mathrm{~Hz})$ & $\mathrm{H}-11$ & C-3, C-10a & $\mathrm{H}-3, \mathrm{H}-11$ \\
\hline \multicolumn{6}{|l|}{2} \\
\hline 3 & 61.8 & $4.04(1 \mathrm{H}, \mathrm{m})$ & $H-4 \alpha, H-12 \alpha$ & & $H-1, H-4 \alpha, H-12 \alpha$ \\
\hline $4 \alpha$ & 25.1 & $1.75(1 \mathrm{H}, \mathrm{dd}, J=11.7,15.1 \mathrm{~Hz})$ & $\mathrm{H}-3$ & $\mathrm{C}-3, \mathrm{C}-4 \mathrm{a}, \mathrm{C}-12$ & $\mathrm{H}-4 \beta$ \\
\hline $4 \beta$ & & $2.65(1 \mathrm{H}, \mathrm{dd}, J=4.1,15.8 \mathrm{~Hz})$ & & C-4a, C-5, C-10a & $H-3, H-4 \alpha$ \\
\hline $4 a$ & 63.5 & & & & \\
\hline 5 & 194.4 & & & & \\
\hline $5 a$ & 112.1 & & & & \\
\hline 6 & 154.6 & & & & \\
\hline $6-\mathrm{OH}$ & & $11.73(1 \mathrm{H}, \mathrm{brs})$ & & C-5, C-5a, C-6, C-7 & \\
\hline 7 & 135.4 & $7.40(1 \mathrm{H}, \mathrm{s})$ & & C-5, C-5a, C-8, C-9 & \\
\hline 8 & 130.2 & & & & \\
\hline 9 & 153.8 & & & & \\
\hline 9-OH & & $11.39(1 \mathrm{H}, \mathrm{brs})$ & & C-8, C-9, C-9a & \\
\hline $9 a$ & 112.2 & & & & \\
\hline 10 & 195.8 & & & & \\
\hline $10 a$ & 63.4 & & & & \\
\hline 11 & 15.8 & $1.50(3 \mathrm{H}, \mathrm{d}, J=6.2 \mathrm{~Hz})$ & $\mathrm{H}-1$ & C-1, C-10a & $\mathrm{H}-1$ \\
\hline $12 \alpha$ & 40.8 & $2.49(1 \mathrm{H}, \mathrm{dd}, J=4.1,15.8 \mathrm{~Hz})$ & & & $\mathrm{H}-4 \alpha, \mathrm{H}-12 \beta$ \\
\hline $12 \beta$ & & $2.25(1 \mathrm{H}, \mathrm{dd}, J=8.9,15.8 \mathrm{~Hz})$ & $\mathrm{H}-3$ & C-3, C-4, C-13 & $\mathrm{H}-12 \alpha$ \\
\hline 13 & 172.5 & & & & \\
\hline $13-\mathrm{OH}$ & & $\delta 12.21(1 \mathrm{H}, \mathrm{brs})$ & & & \\
\hline
\end{tabular}

aAll NMR spectra were measured in DMSO- $d_{6}$. 
Table 2 Biological activities of compound 1

\begin{tabular}{lr}
\hline Test organisms & $M I C\left(\mu g l^{-1}\right)$ \\
\hline Staphylococcus aureus (MRSA) & 32 \\
Staphylococcus aureus (MSSA) & 16 \\
Bacillus subtilis & 8 \\
Escherichia coli & $>500$ \\
Pseudomonas putida & $>500$ \\
Saccharomyces sereviesae & $>500$ \\
\hline
\end{tabular}

4a and C-10a) are adjacent to each other and act as the bridgeheads of the fused rings. These carbons likely form an epoxide ring because only one oxygen atom remained for these carbons according to the molecular formula. Figure 1 also indicates a HMBC correlation between one aromatic proton and two hydrogen-bonded phenolic hydroxyl protons ( $\mathrm{H}-7$ to $\mathrm{C}-5, \mathrm{C}-5 \mathrm{a}, \mathrm{C}-8$ and $\mathrm{C}-9 ; 6-\mathrm{OH}$ to $\mathrm{C}-5$, C-5a, C-6 and C-7; 9-OH to C-8, C-9 and C-9a). The bound position of two symmetric monomers is revealed to be $\mathrm{C}-8$, which contains a position of non-protonated aromatic carbon that bridges the carbon of the dihydroxynaphthoquinone skeleton and an oxygenated carbon.

The determined structure of compound $\mathbf{1}$ is closely related to a pyranonaphthoquinone antibiotic, actinorhodin, ${ }^{1}$ which is also a symmetric dimer. The monomeric structural difference between compound $\mathbf{1}$ and actinorhodin is the presence of an epoxide or a double bond between C-4a and C-10a. Compound 1 has two more oxygen atoms than actinorhodin as determined by comparison of their molecular formulas. Carbon signals from C-4a and C-10a in compound 1 were observed at $\delta_{\mathrm{C}} 63.5$ and 63.4 p.p.m., respectively, and were extremely higher than those of the corresponding carbon signals in actinorhodin $\left(\delta_{\mathrm{C}} 124.4\right.$ and 125.0). ${ }^{1}$ The existence of two additive oxygen atoms and four oxygenated sp3 carbon signals (C-4a, C-4'a, C-10a, and C-10'a) obviously suggested the two epoxides form in compound $\mathbf{1}$. Thus, the planer configuration of compound $\mathbf{1}$ is $4 \mathrm{a}$, 10a- and 4'a, 10'a- diepoxyactinorhodin. Finally, the ROESY correlations between $\mathrm{H}-11$ and $\mathrm{H}-3$; $\mathrm{H}-3$ and $\mathrm{H}-4 \alpha$ disclosed the configuration, as shown in Table 1 and Figure 2. All assignments of ${ }^{1} \mathrm{H}$ and ${ }^{13} \mathrm{C}$ NMR signals and the connectivity between each proton and carbon are shown in Table 1.

Pyranonaphthoquinone-family antibiotics have been isolated from various strains of bacteria, actinomycetes and fungi. ${ }^{2}$ This class possesses the monomeric naphtho[2,3-c]pyran-5,10-dione ring system in common. Kalafungin, ${ }^{3}$ nanaomycin ${ }^{4}$ and guriseucin ${ }^{5}$ have an additional lactone ring, carboxylic acid side-chain and sugar-like moieties, respectively. In addition, these monomeric pyranonaphthoquinone compounds often form a dimeric structure with direct C-C bond formation (for example, actinorhodin ${ }^{6}$ and crisamicin $^{7}$ ). In general, this family of antibiotics possesses a broad range of biological activities against gram-positive bacteria and pathogenic fungi, along with antiviral and antitumor activity. ${ }^{1}$

Antibacterial activities of compound 1 against Bacillus subtilis, Escherichia coli, Pseudomonas putida and Staphylococcus aureus were determined using the microtiter plate method with LB agar medium inoculated with each bacterium for $24 \mathrm{~h}$ at $37^{\circ} \mathrm{C}$ (Table 2). Compound 1 appears to possess similar activities against gram-positive bacteria as actinorhodin $\left(25-30 \mu \mathrm{g} \mathrm{ml}^{-1}\right),{ }^{8}$ and was not active toward gram-negative bacteria or fungi, which is consistent with the activity of other monomer or dimer-type pyranonaphthoquinone antibiotics.

1 Charles, P. G., Brian, A. M. R., Ching, C. \& Heinz, G. F. Biosynthesis of actinorhodin. Determination of the point of dimerization. J. Org. Chem. 46, 455-456 (1981).

2 Brimble, M. A., Duncalf, L. J. \& Nairn, M. R. Pyranonaphthoquinone antibioticsisolation, structure and biological activity. Nat. Prod. Rep. 16, 267-281 (1999).

3 Bergy, M. E. Kalafungin. A new broad spectrum antibiotic. Isolation and characterization. J. Antibiot. 21, 454-457 (1968).

4 Omura, S. et al. Nanaomycins A and B, new antibiotics produced by a strain of Streptomyces. J. Antibiot. 27, 363-365 (1974).

5 Tsuji, N. et al. New antibiotics, griseusins A and B. Isolation and characterization. J. Antibiot. 29, 7-9 (1976).

6 Brockmann, H., Zeeck, A., van der Merwe, K. \& Muller, W. Actinomycetes dyes. VIII. Structure of actinorhodin. Justus Leibigs Ann Chem. 698, 209-229 (1966).

7 Ling, D., Shield, L. S. \& Rinehart, K. L. Jr. Isolation and structure determination of crisamicin A, a new antibiotic from Micromonospora purpureochromogenes subsp. halotolerans. J. Antibiot. 39, 345-353 (1986).

8 Wright, L. H. \& Hopwood, D. A. Actinorhodin is a chromosomally-determined antibiotic in Streptomyces coelicolor A3(2). J. Gen. Microbiol. 96, 289-297 (1976). 